\title{
Comparison of silicon oxide and silicon carbide absorber materials in silicon thin-film solar cells
}

\author{
Cordula Walder ${ }^{1, a}$, Martin Kellermann ${ }^{1}$, Elke Wendler ${ }^{2}$, Jura Rensberg ${ }^{2}$, Karsten von Maydell ${ }^{1}$, and Carsten Agert ${ }^{1}$ \\ 1 NEXT ENERGY · EWE Research Centre for Energy Technology at the University of Oldenburg, Carl-von-Ossietzky-Straße \\ 15, 26129 Oldenburg, Germany \\ 2 Institut für Festkörperphysik, Friedrich-Schiller-Universität Jena, Helmholtzweg 3, 07743 Jena, Germany
}

Received: 30 September 2014 / Received in final form: 22 January 2015 / Accepted: 23 January 2015

Published online: 23 February 2015

(C) Walder et al., published by EDP Sciences, 2015

\begin{abstract}
Since solar energy conversion by photovoltaics is most efficient for photon energies at the bandgap of the absorbing material the idea of combining absorber layers with different bandgaps in a multijunction cell has become popular. In silicon thin-film photovoltaics a multijunction stack with more than two subcells requires a high bandgap amorphous silicon alloy top cell absorber to achieve an optimal bandgap combination. We address the question whether amorphous silicon carbide (a-SiC:H) or amorphous silicon oxide $(\mathrm{a}-\mathrm{SiO}: \mathrm{H})$ is more suited for this type of top cell absorber. Our single cell results show a better performance of amorphous silicon carbide with respect to fill factor and especially open circuit voltage at equivalent Tauc bandgaps. The microstructure factor of single layers indicates less void structure in amorphous silicon carbide than in amorphous silicon oxide. Yet photoconductivity of silicon oxide films seems to be higher which could be explained by the material being not truly intrinsic. On the other hand better cell performance of amorphous silicon carbide absorber layers might be connected to better hole transport in the cell.
\end{abstract}

\section{Introduction}

In silicon thin-film photovoltaics multijunction solar cells are a promising concept for efficiency enhancement by reducing thermalization losses in the absorber material and increasing the overall light absorption. For this purpose subcells with optimal absorber layer bandgaps should be combined in a layer stack. Yunaz et al. [1] have shown that in a triple cell structure with a bottom cell bandgap of $1.1 \mathrm{eV}$ the optimal bandgap of the top cell absorbing material exceeds the standard value of amorphous silicon. Consequently high bandgap amorphous silicon alloys containing carbon, oxygen or both are considered as absorber materials for the top cell. Their single layer properties have been studied for some time [2-8] and recently their applicability in single and multijunction cells has been confirmed [9-13]. Yet it is unclear which amorphous silicon alloy is preferable as top cell absorber. Haga et al. [5] and Fujikake et al. [6] observed the photoconductivity of a$\mathrm{SiO}: \mathrm{H}$ to be higher by orders of magnitude compared to a-SiC:H at similar optical bandgaps. However photoconductivity does not always relate to cell performance if the absorber material is not truly intrinsic [14]. Therefore the

${ }^{a}$ e-mail: cordula.walder@next-energy . de objective of our work is to compare single layer and single cell properties of a-SiO:H and a-SiC:H to see which material shows better results as a high bandgap absorber layer.

\section{Experimental methods}

All amorphous silicon materials were deposited by PECVD (plasma enhanced chemical vapor deposition) at $13.57 \mathrm{MHz}$ at the cluster tool from Von Ardenne where separate chambers are available for intrinsic and doped layers. We created amorphous silicon single cells according to the layer stack in Figure 1 with $1 \mathrm{~cm}^{2}$ cell area defined by the size of the silver back contact. High bandgap absorber layers were achieved by introducing either carbon dioxide or methane as additional source gas to silane and hydrogen in the intrinsic layer. All process conditions (see Tab. 1) were kept constant except the methane or carbon dioxide flow which was varied in order to compare the influence of carbon and oxygen in the absorber material. For each single cell we also produced single layers at the process conditions used for the cell absorber. Cells were deposited on commercial rough NSG (Nippon Sheet Glass) which comprises $\mathrm{SnO}_{2}: \mathrm{F}$ as TCO electrode. Single 
EPJ Photovoltaics

Table 1. Summary of the deposition parameters used in this work.

\begin{tabular}{lccccc}
\hline & p-a-SiO:H & i-a-Si:H & i-a-SiO:H & i-a-SiC:H & n-a-Si:H \\
\hline$\phi\left(\mathrm{H}_{2}\right)[\mathrm{sccm}]$ & 200 & 200 & 900 & 900 & 200 \\
$\phi\left(\mathrm{SiH}_{4}\right)[\mathrm{sccm}]$ & 25 & 40 & 30 & 30 & 40 \\
$\phi\left(\mathrm{CO}_{2}\right)[\mathrm{sccm}]$ & 50 & & $3-20$ & & \\
$\phi\left(\mathrm{CH}_{4}\right)[\mathrm{sccm}]$ & & & & $7-30$ & \\
$\phi\left(\mathrm{B}_{2} \mathrm{H}_{6}\right)[\mathrm{sccm}]$ & 32 & & & & \\
$\phi\left(\mathrm{PH}_{3}\right)[\mathrm{sccm}]$ & & & & & 25 \\
$P[\mathrm{~W}]$ & 10 & 10 & 10 & 10 & 15 \\
$p[\mathrm{mbar}]$ & 0.3 & 1 & 1 & 1 & 1 \\
$d_{\mathrm{el}}[\mathrm{mm}]$ & 25 & 15 & 15 & 15 & 20 \\
$T_{\text {sub }}\left[{ }^{\circ} \mathrm{C}\right]$ & 220 & 220 & 180 & 180 & 220 \\
\hline
\end{tabular}

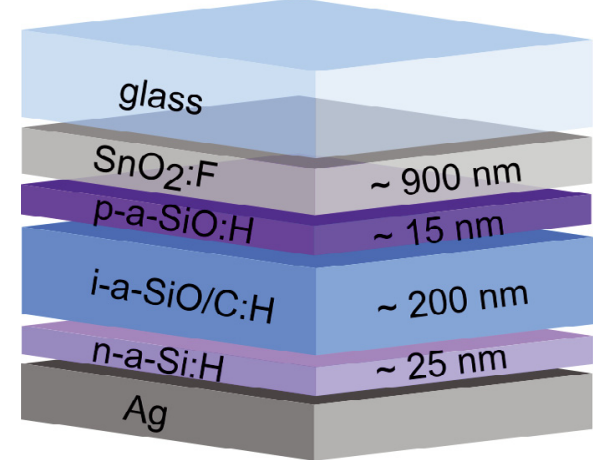

Fig. 1. Layer stack of a-SiO:H and a-SiC:H single cells.

layers were produced on commercial Schott Eco glass and on monocrystalline silicon wafer pieces polished on both sides to enable infrared transmission measurements.

Single cells were characterized by illuminated current voltage measurements (IV) using a WACOM dual lamp solar simulator under standard test conditions (AM1.5G spectrum, $1000 \mathrm{~W} / \mathrm{m}^{2}, 25{ }^{\circ} \mathrm{C}$ cell temperature). The optical Tauc bandgap [15] and the corresponding Tauc slope parameter B of single layers were determined from reflection and transmission measurements with the UV-VISNIR spectrometer Cary 5000 from Varian. Fourier transformed infrared spectra of single layers on silicon wafers were taken with the FTIR spectrometer Spectrum 400 from Perkin Elmer. The strength of the resulting absorption peaks was analysed with the software Scout/Code by W. Theiss Hard- and Software. The hydrogen concentration was calculated from the $2000 \mathrm{~cm}^{-1}$ band of $\mathrm{Si}-\mathrm{H}$ stretching modes according to the relation given by Lucovsky et al. [16]:

$$
\text { conc. }(\mathrm{H})=0.77 \frac{\mathrm{at} . \%}{\mathrm{eV} \mathrm{cm}^{-1}} \int \alpha d E \text {. }
$$

The microstructure factor was obtained from the absorption strength of polyhydrogen modes divided by that of all hydrogen modes around the wavenumber $\nu=2000 \mathrm{~cm}^{-1}$. For conductivity measurements single layer samples were evaporated with coplanar aluminum pads having $1 \mathrm{~cm}$ length and $1 \mathrm{~mm}$ gap in between. These samples were placed in a vacuum atmosphere of ca. $10^{-6}$ mbar and their current voltage characteristics were taken with the electrometer 6517B from Keithley. Photoconductivity was measured the same way using a blue LED lamp. Constant photocurrent measurements (CPM) were conducted with the same sample geometry to calculate the Urbach energy from the exponential decay of the absorption coefficient at low photon energies. Oxygen and carbon concentrations were obtained from elastic (non-Rutherford) backscattering spectrometry (EBS). In contrast to conventional Rutherford backscattering spectrometry this method utilizes the enhancement of the scattering cross-section of $\mathrm{He}^{+/++}$ions on ${ }^{12} \mathrm{C}\left({ }^{16} \mathrm{O}\right)$ by a factor of more than 120 (20) at a $\mathrm{He}^{+/++}$ion energy of $5700 \mathrm{keV}(3035 \mathrm{keV})$. The carbon (oxygen) content can be determined by comparing the backscattering yield of each sample with the backscattering yield of a reference sample of known carbon (oxygen) concentration after subtracting the silicon background. Here, glassy carbon and a $1 \mu \mathrm{m}$ thick thermal $\mathrm{SiO}_{2}$ layer on a $\mathrm{Si}$ substrate were used as references.

\section{Results}

\subsection{Single cell results}

Amorphous silicon alloy single cells were produced with varying flows of either $\mathrm{CO}_{2}$ or $\mathrm{CH}_{4}$ in the intrinsic layer. Figure 2 shows open circuit voltage, fill factor, short circuit current and efficiency of these solar cells as a function of the Tauc bandgap which was measured on equivalent single layers. The addition of either $\mathrm{CO}_{2}$ or $\mathrm{CH}_{4}$ leads to a rise in open circuit voltage compared to the reference cells without carbon or oxygen in the intrinsic layer (Fig. 2a). Cells deposited with $\mathrm{CH}_{4}$ reach higher values of open circuit voltage ( $V_{\mathrm{OC}}$ up to $1000 \mathrm{mV}$ ) than cells deposited with $\mathrm{CO}_{2}\left(V_{\mathrm{OC}}\right.$ up to $\left.920 \mathrm{mV}\right)$. While there is a rising tendency of open circuit voltage with Tauc bandgap for $\mathrm{CH}_{4}$ in the case of $\mathrm{CO}_{2}$ the open circuit voltage remains approximately constant after a first increase. Since $\mathrm{CO}_{2}$ and $\mathrm{CH}_{4}$ introduce defects into the intrinsic material $[7,8]$ the fill factor decreases with rising Tauc bandgap in both cases but takes higher values for cells with $\mathrm{CH}_{4}$ (Fig. 2b). The short circuit current drops significantly at the first addition of $\mathrm{CO}_{2}$ or $\mathrm{CH}_{4}$ and starts to decrease with the bandgap as expected (Fig. 2c). $\mathrm{CO}_{2}$ and $\mathrm{CH}_{4}$ have a similar influence on the short circuit current with 
C. Walder et al.: Comparison of silicon oxide and silicon carbide absorber materials

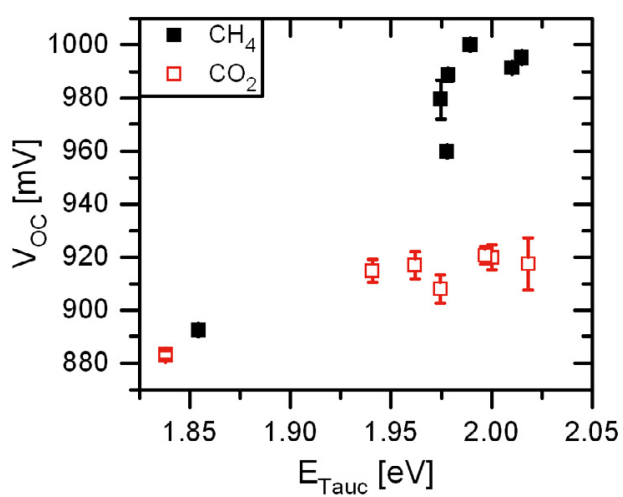

(a)

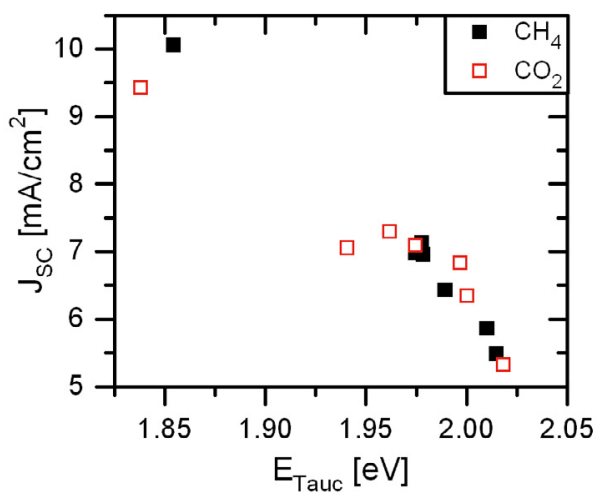

(c)

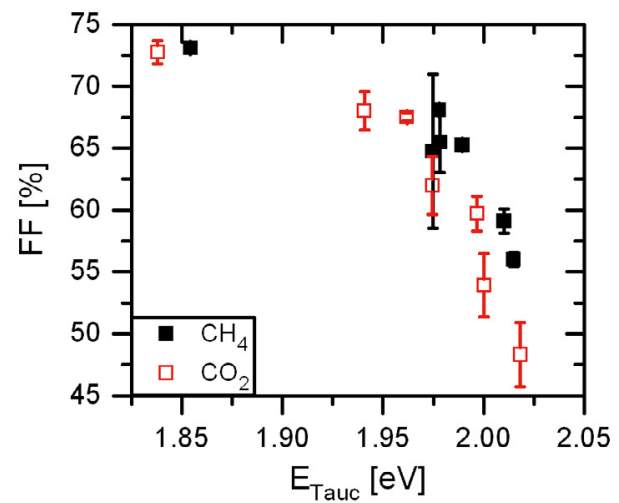

(b)

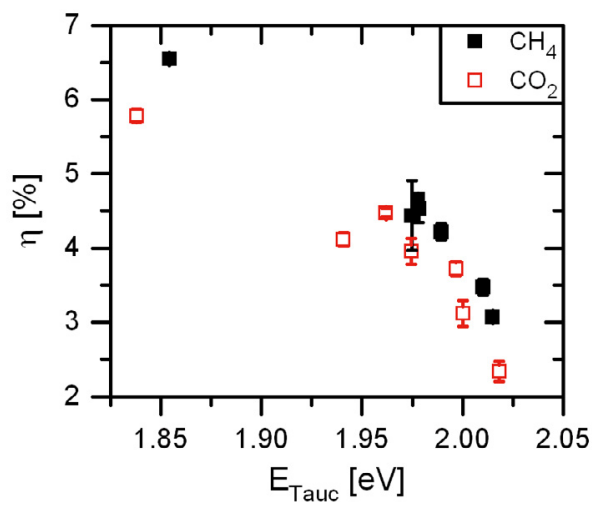

(d)

Fig. 2. IV parameters of amorphous silicon alloy single cells produced with $\mathrm{CO}_{2}$ or $\mathrm{CH}_{4}$ in the intrinsic layer against Tauc bandgap.

respect to the Tauc bandgap. Although the difference between the highest efficiencies reached with $\mathrm{CO}_{2}$ and $\mathrm{CH}_{4}$ is relatively small $(0.2 \%)$ the results of the current voltage characteristics clearly favor $\mathrm{CH}_{4}$ because open circuit voltage and fill factor are predominant factors in the development of high voltage top cells while the current can be adjusted by the cell thickness and light management.

\subsection{Single layer results}

Single layers corresponding to the intrinsic cell absorbers were deposited on Schott Eco glass and double sided polished monocrystalline silicon wafers. In Figure 3 the oxygen and carbon concentrations determined by EBS are shown as a function of the $\mathrm{CO}_{2}$ or $\mathrm{CH}_{4}$ gas flow. With increasing gas flow the concentrations of carbon and oxygen rise approximately linearly. The increase of the oxygen concentration with $\mathrm{CO}_{2}$ flow is almost twice as high as that of the carbon concentration with an equivalent $\mathrm{CH}_{4}$ flow. When $\mathrm{CO}_{2}$ is used the incorporated carbon concentration even for the highest flow remains below 1 at.\%.

Figure 4 shows the optical Tauc bandgap $E_{\text {Tauc }}$ of the films prepared with $\mathrm{CO}_{2}$ or $\mathrm{CH}_{4}$ as a function of the oxygen or carbon concentration. The Tauc bandgap first rises steeply and then more gently with the concentration. At

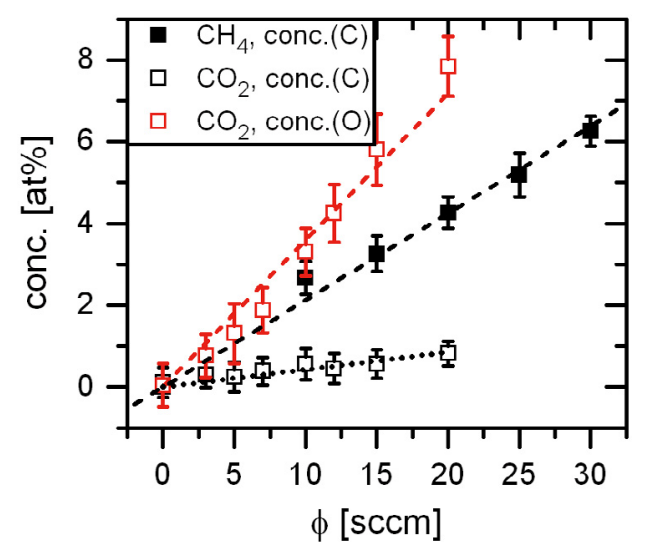

Fig. 3. $\mathrm{C}$ and $\mathrm{O}$ concentration from EBS of amorphous silicon alloy single layers against $\mathrm{CH}_{4}$ or $\mathrm{CO}_{2}$ flow.

equivalent oxygen and carbon concentrations there is no significant difference in the values of the Tauc bandgap for the films prepared with $\mathrm{CO}_{2}$ or $\mathrm{CH}_{4}$. This is an interesting result, since oxygen and carbon have different binding energies with silicon.

Infrared transmission measurements show the typical absorption band of $\mathrm{Si}-\mathrm{H}$ stretching vibrations around the wavenumber of $\nu=2000 \mathrm{~cm}^{-1}$. In Figure 5 the hydrogen 
EPJ Photovoltaics

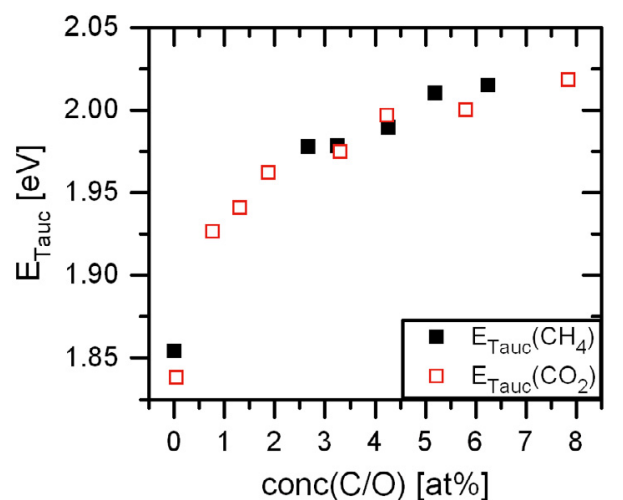

Fig. 4. Tauc bandgap of amorphous silicon alloy single layers against $\mathrm{C}$ or $\mathrm{O}$ concentration from EBS.

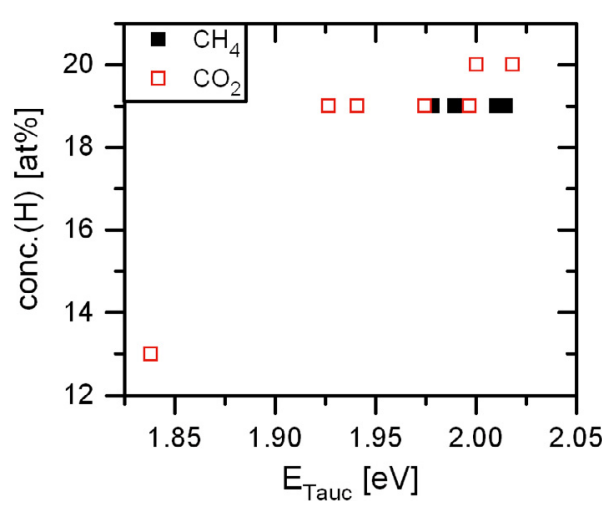

Fig. 5. Hydrogen concentration deduced from Si-H stretching modes around the wavenumber $\nu=2000 \mathrm{~cm}^{-1}$ for amorphous silicon alloy single layers produced with $\mathrm{CO}_{2}$ or $\mathrm{CH}_{4}$ on c-Si wafers.

concentration according to formula (1) is depicted for single layers prepared with $\mathrm{CO}_{2}$ or $\mathrm{CH}_{4}$ in dependence on the Tauc bandgap. The alloys with oxygen or carbon are prepared at a 6 times higher hydrogen dilution than the reference sample and consequently show a higher hydrogen content of about 20 at.\% compared to 13 at.\% for the reference. Almost no difference in hydrogen content can be detected for all silicon carbide and silicon oxide samples regardless of the source gas or the Tauc bandgap. In Figure 6 the squared oscillator strength of the $\mathrm{Si}-\mathrm{H}_{2}$ bend-scissors IR mode at $\nu=880 \mathrm{~cm}^{-1}$ is presented. It is proportional to the integrated absorption coefficient of this mode and therefore is a measure for the amount of $\mathrm{Si}-\mathrm{H}_{2}$ bonds which are known to promote degradation effects. For $\mathrm{CO}_{2}$ and $\mathrm{CH}_{4}$ the amount of $\mathrm{Si}-\mathrm{H}_{2}$ bonds rises with increasing bandgap indicating a deterioration of material quality. Yet for $\mathrm{CH}_{4}$ it is considerably lower than for $\mathrm{CO}_{2}$ at equivalent bandgaps. Figure 7 shows the microstructure factor for films prepared with $\mathrm{CO}_{2}$ or $\mathrm{CH}_{4}$ as a function of the Tauc bandgap. The microstructure factor mirrors the trend of the amount of $\mathrm{Si}-\mathrm{H}_{2}$ bonds as expected. It rises steeply from 0.24 to 0.72 for films prepared with $\mathrm{CO}_{2}$ and more moderately from 0.12 to 0.22 for films prepared with $\mathrm{CH}_{4}$.

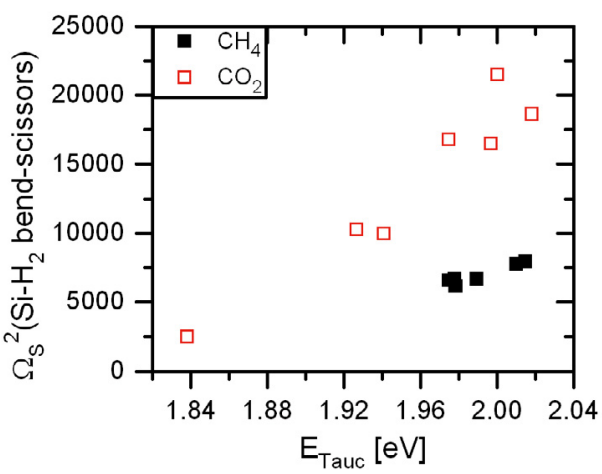

Fig. 6. Squared oscillator strength of $\mathrm{Si}-\mathrm{H}_{2}$ bend-scissors IR mode at $\nu=880 \mathrm{~cm}^{-1}$ for amorphous silicon alloy single layers produced with $\mathrm{CO}_{2}$ or $\mathrm{CH}_{4}$ on c-Si wafers.

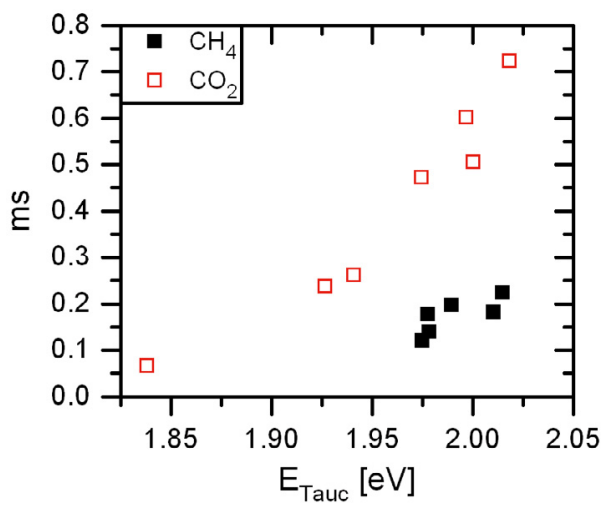

Fig. 7. Microstructure factor ms of amorphous silicon alloy single layers produced with $\mathrm{CO}_{2}$ or $\mathrm{CH}_{4}$ on c-Si wafers.

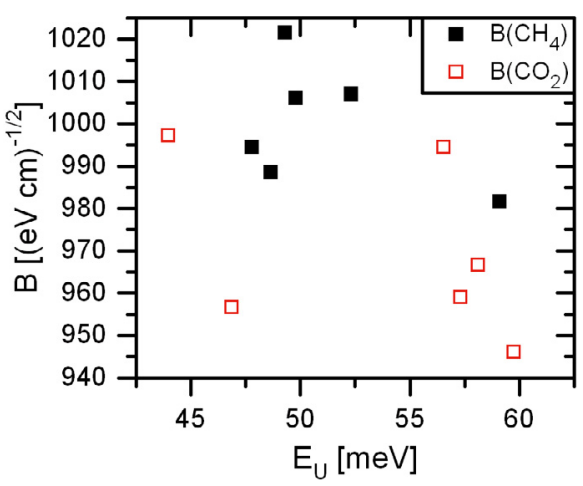

Fig. 8. Tauc slope parameter $\mathrm{B}$ of amorphous silicon alloy single layers produced with $\mathrm{CO}_{2}$ or $\mathrm{CH}_{4}$ against Tauc bandgap.

The Tauc slope parameter B represents the steepness of the absorption coefficient over energy and therefore is an indicator of material quality. Figure 8 illustrates the Tauc slope parameter against the Urbach energy for samples prepared with $\mathrm{CO}_{2}$ or $\mathrm{CH}_{4}$. Samples prepared with $\mathrm{CH}_{4}$ tend to achieve higher $\mathrm{B}$ parameters and lower Urbach energies compared to samples prepared with $\mathrm{CO}_{2}$. This suggests less disorder and less bond angle distortion in the case of $\mathrm{CH}_{4}$ compared to $\mathrm{CO}_{2}$. Otherwise it is difficult to make out a clear relationship between the Tauc slope parameter and the Urbach energy. Ambrosone et al. [17] 


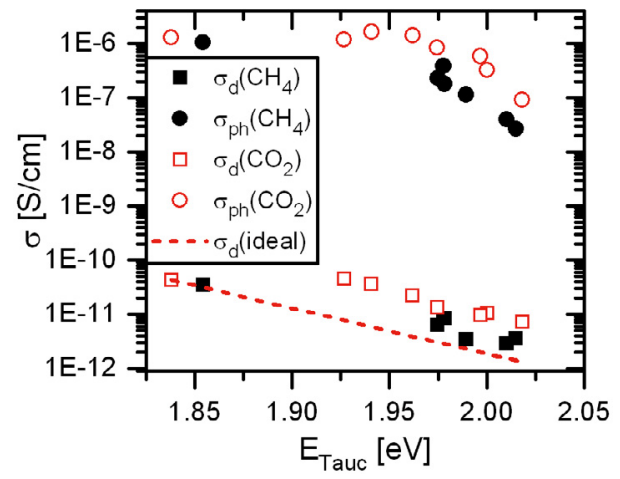

Fig. 9. Dark and photoconductivity of amorphous silicon alloy single layers produced with $\mathrm{CO}_{2}$ or $\mathrm{CH}_{4}$ against Tauc bandgap at room temperature.

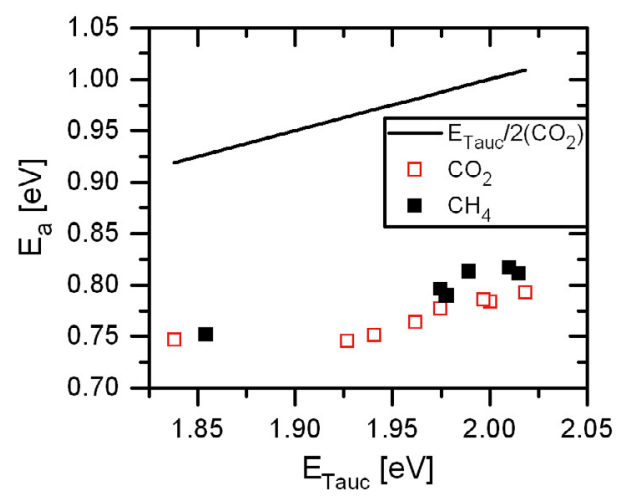

Fig. 10. Activation energy of amorphous silicon alloy single layers produced with $\mathrm{CO}_{2}$ or $\mathrm{CH}_{4}$ against Tauc bandgap at room temperature.

observe how the Tauc slope parameter decreases from 788 to $663(\mathrm{eV} \mathrm{cm})^{-1 / 2}$ with rising Urbach energy in a range from 72 to $170 \mathrm{meV}$. This trend is not clearly demonstrated by our results since the variation in Urbach energy is quite small.

In Figure 9 dark and photoconductivity measurements for films prepared with $\mathrm{CO}_{2}$ or $\mathrm{CH}_{4}$ are depicted. As expected dark and photoconductivity both decrease at higher bandgaps. Yet the films prepared with $\mathrm{CO}_{2}$ show higher photoconductivity by half an order of magnitude compared to $\mathrm{CH}_{4}$ which seems to contradict our remaining results. Figure 10 shows the activation energy calculated from the dark conductivity at room temperature with a constant conductivity prefactor of $\sigma_{0}=150 \mathrm{~S} / \mathrm{cm}$ as proposed in reference [18]. The activation energy increases with the Tauc bandgap and takes slightly lower values for samples prepared with $\mathrm{CO}_{2}$ compared to those prepared with $\mathrm{CH}_{4}$. Half the Tauc bandgap is also depicted for comparison since it should be close to the activation energy of truly intrinsic layers.

\section{Discussion}

The addition of either $\mathrm{CH}_{4}$ or $\mathrm{CO}_{2}$ as source gases for high bandgap amorphous silicon alloys leads to the incor- poration of carbon or oxygen into the amorphous silicon network. Although $\mathrm{CO}_{2}$ contains carbon almost no carbon is incorporated into the layer in agreement with previous results [6]. As can be seen in Figure 3 oxygen is incorporated more easily into the network since higher oxygen than carbon concentrations are reached at equivalent flows of $\mathrm{CO}_{2}$ and $\mathrm{CH}_{4}$. This can be explained by the higher energy required for the dissociation of $\mathrm{CH}_{4}$ compared to $\mathrm{CO}_{2}[19,20]$. Furthermore Bullot and Schmidt [21] suggest that in the low power regime $\mathrm{CH}_{4}$ is only dissociated by secondary reactions with silicon species but not directly by electron impact.

The Tauc bandgap rises first steeply and then more gently with oxygen or carbon concentration (see Fig. 4). The initial steep increase is promoted by much higher hydrogen dilution and therefore higher hydrogen incorporation in the alloyed samples compared to the a-Si:H reference (see Tab. 1 and Fig. 5). Hydrogen is well-known to increase the bandgap of amorphous silicon and its alloys [22]. Further increase in the bandgap with oxygen or carbon concentration is explained by higher binding energies and backbonding effects of oxygen or carbon with silicon [7]. Yet oxygen has a higher bond strength with silicon than carbon and therefore should produce a higher bandgap at equivalent concentrations [23] which is not observed in our results. Possibly this is due to the silicon carbide layers having a higher hydrogen content than the silicon oxide films. While $\mathrm{CH}_{4}$ is known to promote hydrogen incorporation [24] $\mathrm{CO}_{2}$ has been observed to suppress it [25]. If hydrogen is bonded in $\mathrm{CH}_{3}$ groups in the silicon carbide films the difference in hydrogen concentration to the silicon oxide films is not observable in the FTIR mode at $\nu=2000 \mathrm{~cm}^{-1}$ used in Figure 5. Moreover the determination of the hydrogen concentration with formula (1) introduces large uncertainties especially with respect to amorphous silicon alloys instead of just a-Si:H.

Single cell results reveal much higher open circuit voltage and slightly higher fill factor in dependence on the Tauc bandgap for $\mathrm{CH}_{4}$ than for $\mathrm{CO}_{2}$. Furthermore the open circuit voltage rises with the Tauc bandgap in case of $\mathrm{CH}_{4}$ while for $\mathrm{CO}_{2}$ it stays almost constant. This can be explained by better material quality of the silicon carbide layers since the microstructure factor and the amount of $\mathrm{Si}_{-} \mathrm{H}_{2}$ bonds suggest a more compact material compared to the layers prepared with $\mathrm{CO}_{2}$. In contrast Beyer found a bigger void structure for amorphous silicon alloys with 18 at.\% carbon concentration than for those with 23 at.\% oxygen concentration from effusion measurements [26]. This indicates that either process conditions change the observed trends considerably or that low carbon and oxygen concentrations lead to a different behavior, since the investigated samples show concentrations below 8 at.\% which is about a factor of 2-3 lower than in the case of Beyer.

Unlike our remaining results conductivity measurements seem to indicate better performance of samples prepared with $\mathrm{CO}_{2}$ than with $\mathrm{CH}_{4}$ in agreement with Haga et al. [5] and Fujikake et al. [6]. One explanation could be an unintentional doping effect especially in the 
silicon oxide films. According to Beck et al. [14] photoconductivity only relates well to cell performance if the absorber material is truly intrinsic. Figure 9 shows that dark conductivity of silicon oxide only starts to decrease at higher Tauc bandgaps and not immediately as expected. The dashed line represents the ideal dark conductivity at room temperature if the Fermi level energy is half the Tauc bandgap energy:

$$
\sigma_{d}(\text { ideal })=\sigma_{0} \exp \left\{-0.5 \frac{E_{\text {Tauc }}}{k T}\right\} .
$$

The conductivity prefactor $\sigma_{0}$ was kept constant and calibrated so that $\sigma_{d}$ (ideal) matches the dark conductivity values of the reference samples at low Tauc bandgaps. Obviously the dark conductivity of silicon carbide is closer to the ideal curve than that of silicon oxide. Both materials are expected to be rather n-type and oxygen is known to act as a donor in the form of $\mathrm{O}_{3}^{+}$impurities [27]. Figure 10 suggests that $\mathrm{CO}_{2}$ produces slightly lower activation energy than $\mathrm{CH}_{4}$. Maybe unintentional n-doping leads to increased conductivity of the silicon oxide films but to worse cell performance compared to silicon carbide. Another explanation for the discrepancy between photoconductivity and cell results could be that cell performance also depends on hole carrier transport which is not monitored by our conductivity measurements. Wang et al. report that hole carrier collection is strongly deteriorated with increased oxygen concentration of amorphous silicon oxide absorber layers in single cells [18]. So it is possible that silicon carbide allows better hole carrier transport than silicon oxide at equivalent bandgaps when used as absorber layers in amorphous silicon single cells.

\section{Conclusion}

The objective of this work was to compare $\mathrm{CO}_{2}$ and $\mathrm{CH}_{4}$ as source gases for high bandgap amorphous silicon alloy absorber layers. Single cell results reveal higher fill factors and especially higher open circuit voltages for $\mathrm{CH}_{4}$ in contrast to $\mathrm{CO}_{2}$ at equivalent Tauc bandgaps. The microstructure factor from infrared transmission measurements indicates that the reason for this might be less voids in the structure of silicon carbide and consequently better material quality of layers produced with $\mathrm{CH}_{4}$. Curiously photoconductivity shows higher values in the case of $\mathrm{CO}_{2}$. One reason for this discrepancy could be higher unintentional n-doping in silicon oxide samples by $\mathrm{O}_{3}^{+}$impurities. Another explanation could be better hole carrier transport when silicon carbide absorber layers are used.

We would like to thank Ulrich Barth for his support with EBS measurements as well as Tim Möller and Ulrike Kochan for their help with UV-VIS optical measurements.

\section{References}

1. I.A. Yunaz, A. Yamada, M. Konagai, Jpn J. Appl. Phys. 46, L1152 (2007)

2. B.G. Yacobi, R.W. Collins, G. Moddel, P. Viktorovitch, W. Paul, Phys. Rev. B 24, 5907 (1981)

3. Y. Tawada, K. Tsuge, M. Kondo, H. Okamoto, Y. Hamakawa, J. Appl. Phys. 53, 5274 (1982)

4. A. Morimoto, T. Miura, M. Kumeda, Jpn J. Appl. Phys. 21, L119 (1982)

5. K. Haga, K. Yamamoto, M. Kumano, Jpn J. Appl. Phys. 25, L39 (1986)

6. S. Fujikake, H. Ohta, A. Asano, Y. Ichikawa, H. Sakai, Mater. Res. Soc. Symp. Proc. 258, 875 (1992)

7. D. Das, S.M. Iftiquar, A.K. Barua, J. Non-Cryst. Solids 210, 148 (1997)

8. A. Desalvo, F. Giorgis, C.F. Pirri, E. Tresso, P. Rava, J. Appl. Phys. 81, 7973 (1997)

9. I.A. Yunaz, K. Hashizume, S. Miyajima, A. Yamada, M. Konagai, Sol. Energy Mater. Sol. Cells 93, 1056 (2009)

10. I.A. Yunaz, H. Nagashima, D. Hamashita, S. Miyajima, M. Konagai, Sol. Energy Mater. Sol. Cells 95, 107 (2011)

11. S. Inthisang, B. Janthong, P. Sichanugrist, M. Konagai, in 26th European Photovoltaic Solar Energy Conference and Exhibition, Hamburg, 2011, p. 2392

12. K. Sriprapha, A. Hongsingthong, T. Krajangsang, S. Inthisang, S. Jaroensathainchok, A. Limmanee, W. Titiroongruang, J. Sritharathikhun, Thin Solid Films 546, 398 (2013)

13. J. Sritharathikhun, S. Inthisang, T. Krajangsang, A. Limmanee, K. Sriprapha, Thin Solid Films 546, 383 (2013)

14. N. Beck, N. Wyrsch, Ch. Hof, A. Shah, J. Appl. Phys. 79, 9361 (1996)

15. J. Tauc, R. Grigorovici, A. Vancu, Phys. Stat. Sol. 15, 627 (1966)

16. G. Lucovsky, J. Yang, S.S. Chao, J.E. Tyler, W. Czubatyj, Phys. Rev. B 28, 3225 (1983)

17. G. Ambrosone, D.K. Basa, U. Coscia, P. Rava, Thin Solid Films 518, 5871 (2010)

18. S. Wang, V. Smirnov, T. Chen, B. Holländer, X. Zhang, S. Xiong, Y. Zhao, F. Finger, Jpn J. Appl. Phys. 54, 011401 (2015)

19. C.W. Bauschlicher Jr., S.R. Langhoff, Chem. Phys. Lett. 177, 133 (1991)

20. L.F. Spencer, A.D. Callimore, Plasma Chem. Plasma Process. 31, 79 (2010)

21. J. Bullot, M.P. Schmidt, Phys. Stat. Sol. B 143, 345 (1987)

22. A. Singh, E.A. Davis, J. Non-Cryst. Solids 122, 233 (1990)

23. T. Jana, S. Ghosh, S. Ray, J. Mater. Sci. 32, 4895 (1997)

24. D. Kuhman, S. Grammatica, F. Jansen, Thin Solid Films 177, 253 (1989)

25. A. Samanta, D. Das, Sol. Energy Mater. Sol. Cells 93, 588 (2009)

26. W. Beyer, J. Non-Cryst. Solids 266-269, 845 (2000)

27. T. Shimizu, T, Ishii, M. Kumeda, A. Masuda, J. NonCryst. Solids 227-230, 403 (1998)

Cite this article as: Cordula Walder, Martin Kellermann, Elke Wendler, Jura Rensberg, Karsten von Maydell, Carsten Agert, Comparison of silicon oxide and silicon carbide absorber materials in silicon thin-film solar cells, EPJ Photovoltaics 6 , $65302(2015)$. 